Genet. Res., Camb. (1960), 1, pp. 69-90

With 4 plates and 9 text figures

Printed in Great Britain

\title{
Two closely linked genes in the mouse
}

\author{
By H. GRÜNEBERG aNd G. M. TRUSLOVE \\ Medical Research Council Group for Experimental Research \\ in Inherited Diseases, University College, London
}

(Received 1 July 1959)

This paper is dedicated to Professor Paula Hertwig on the
occasion of her seventieth birthday

INTRODUCTION

Cases of closely linked genes with similar phenotypic effects were probably first noticed in Drosophila melanogaster (Grüneberg, 1937). In recent years, numerous instances of a similar kind in viruses, bacteria, fungi and Drosophila have served for the study of the nature of allelism and the fine structure of the gene. In mammals, the only instance of a 'complex locus' is that of the Brachyury and Anury 'alleles' $\left(T, t^{0}, t^{1}\right.$, etc.) in the mouse which has been studied in great detail by Dunn (1956) and his colleagues.

In this paper, a new spotting gene in the mouse will be described which turns out to be closely linked to the well-known gene for dominant spotting with macrocytic anaemia ( $W$ and $W^{v}$ ) in linkage group III. Compared with the simple (biochemical, etc.) phenotypes of most of the microbial genes used for similar studies, the phenotypes of both of these genes in the mouse are a good deal more complicated. The detailed comparison thus made possible reveals several puzzling features for which no obvious explanation can at present be given. Presumably the complexity of the situation here encountered will not prove exceptional and will thus have to be taken into account in the formulation of a general theory of gene structure and gene action.

\section{GENETICS}

The gene to be described in this paper arose as a spontaneous mutation in the C57BL strain maintained by the Glaxo Laboratories (Greenford, Middlesex) in the year 1950. The present stock is derived from an outcross to the inbred strain $\mathrm{CBA} / \mathrm{Gr}$. 'Patch' (symbol $P h$ ), to give it a name, produces spotting rather like that of piebald $(s / s)$ and belted $(b t / b t)$ in the mouse; i.e., areas of pigmented and of white fur are sharply demarcated from each other (Plate I) and there is little intermixture of white and pigmented hairs as in dominant spotting with macrocytic anaemia $\left(W /+\right.$ and $\left.W^{v} /+\right)$. The amount of dorsal white is very variable, but there is always at least a large belly-spot together with extensive tail spotting and white digits, and the classification is thus never in doubt. No other anomalies have been discovered in the living Patch mouse. 
All Patch mice tested (most of them derived from $P h /+\times P h /+$ matings) have proved to be $P h /+$ heterozygotes, and matings between such animals produce a $2: 1$ rather than a $3: 1$ ratio of spotted to self mice (Table 1). The $P h / P h$ homozygote is thus inviable; as will be shown below, it dies before birth.

\section{Table 1. Segregation of Patch}

$\begin{array}{lrrr}\text { Type of mating } & P h /+ & +/+ & \text { Total } \\ P h /+\times+/+ & 192 & 167 & 359 \\ P h /+\times P h /+ & 1052 & 522 & 1574\end{array}$

Tests were carried out to establish the relationship between Patch and some of the known major spotting genes. A cross of a $P h /+$ to a piebald $s / s$ mouse produced two spotted $(P h /+;+/ s)$ and three 'self' $(+/+;+/ s)$ mice; the latter, like most $+/ s$ individuals, had some white on tails and feet. One $P h /+;+/ s$ male was backcrossed to a $+1+; s / s$ female. Ten out of the thirty-seven offspring produced resembled the black-eyed white $(W /+; s / s)$ of the Mouse Fancy; being either completely white, or with small pigmented patches round the eyes, in the ear region or on the haunches. They were thus much whiter than either $P h /+$ or $s / s$ mice and were evidently of the constitution $P h /+; s / s$. Sixteen backcross mice with medium degrees of spotting evidently included the genotypes $P h /+$; $+/ s$ and $+/+; s / s$; and eleven 'selfs' with tail and foot spotting and often with small belly-spots clearly represented the $+/+;+/ s$ class. The appearance of the latter shows that $P h$ and $s$ are not allelic to each other. The 10:16:11 ratio is compatible with a $1: 2: 1$ ratio; hence the two genes are either independent of each other or, at any rate, not closely linked.

A $P h /+;+/ b t$ male (phenotype like $P h /+;+/+$ ) was backcrossed to a $+1+; b t / b t$ (belted) female. Six out of the twenty offspring produced were 'selfs' with white on feet and tails; one had a few white hairs on its belly. These animals are clearly $+1+;+\mid b t$, and thus prove that $P h$ and $b t$ are not alleles. The remaining fourteen spotted mice included some with narrow belts (presumably $+1+; b t / b t$ ), some with wide belts (presumably $P h /+;+\mid b t)$ and some with head and shoulders pigmented while the rest of the body was either completely white or there was a little pigment on the haunches (presumably $P h /+; b t / b t$ ). We shall give no detailed figures, as in a few animals classification by phenotype alone was not beyond doubt.

$P h /+; M i^{w h} /+$ mice resemble $P h /+; b t / b t$ animals in that pigment is confined to head, shoulders and forelegs, with sometimes a little on the haunches; the pigmented areas are dilute due to the effect of $M i^{i \omega h} /+$.

$P h /+; W^{v} /+$ mice are completely white except for an area of the head which is usually like that shown in Text-fig. 1; sometimes the white extends to the tip of the nose so that only the cheeks and ears remain pigmented. The pigmented areas are diluted to a greater extent than can be accounted for by the effect of $W^{v /}+$ alone. Two pairs of such animals produced a small $\mathbf{F}_{2}$ generation (Table 
2), the five viable phenotypes being (1) black-eyed whites, (2) double heterozygotes as described above, (3) Patch with sharply defined areas of spotting and without coat colour dilution, (4) variegated (roan) spotting with dilution of pigment, and

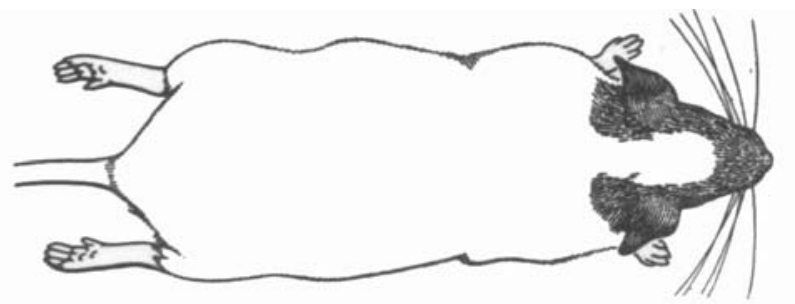

Text-fig. 1. A $P h /+; W^{v} /+$ mouse. Drawing based on photograph.

(5) self. The segregation data show that $P h$ and $W^{v}$ are closely linked. Of the eighty-two gametes which went into the make-up of these forty-one $\mathrm{F}_{2}$ mice, only two are certain recombinants; others might be hidden in class (1), but they are probably few in number.

Table 2. Offspring of two $\mathrm{Ph} /+; \mathrm{W}^{\mathrm{v}} /+\times \mathrm{Ph} /+; \mathrm{W}^{\mathrm{v}} /+$ matings. Expectation on the basis of independent segregation and ignoring the inviable $\mathrm{Ph} / \mathrm{Ph}$ homozygote.

\begin{tabular}{|c|c|c|c|c|}
\hline & \multicolumn{2}{|c|}{ Expected } & \multirow[b]{2}{*}{ Observed } \\
\hline & & Ratio & No. of mice & \\
\hline (1) & $W^{v} / W^{v} ;+/+$ and $W^{v} / W^{v} ; P h /+$ & 3 & $10 \cdot 25$ & 18 \\
\hline (2) & $W^{v} /+; P h /+$ & 4 & $13 \cdot 67$ & 21 \\
\hline (3) & $+/+; P h /+$ & 2 & $6 \cdot 83$ & 1 \\
\hline (4) & $W^{*} /+;+1+$ & 2 & $6 \cdot 83$ & $\mathbf{1}$ \\
\hline (5) & $+1+;+1+$ & 1 & $3 \cdot 42$ & 0 \\
\hline & Total & 12 & $41 \cdot 00$ & 41 \\
\hline
\end{tabular}

$$
\begin{array}{ccccc}
\multicolumn{5}{c}{\text { Table 3. Results of } \frac{\mathrm{Ph}+}{++} \times \frac{++}{+W^{\mathrm{v}}} \text { matings }} \\
\frac{P h+}{+W^{v}} & \frac{++}{+W^{v}} & \frac{P h+}{++} & \frac{++}{++} & \text { Total } \\
142 & 178 & 197 & 212 & 729
\end{array}
$$

Double heterozygotes for more extensive backcross experiments were obtained from the matings summarized in Table 3. Equality of the four classes is expected. The significant deficiency of double heterozygotes indicates a reduced viability which is also obvious from their slow growth and high mortality during the first month or two. The backcross experiment (Table 4) includes a single crossover animal from a total of 1302 mice, or 0.077 per cent. The linkage between $P h$ and 
$W^{v}$ is thus very close. The order of the two genes in relation to a third marker is not yet known.

The $\mathrm{F}_{2}$ and backcross linkage data are not in good agreement with each other. If in the $\mathrm{F}_{2}$ generation there were in fact no more than the two certain crossover

\begin{tabular}{|c|c|c|c|c|c|}
\hline $\begin{array}{c}\text { Sex of } \\
\text { heterozygous } \\
\text { parent }\end{array}$ & $\frac{P h+}{++}$ & $\frac{+W^{v}}{++}$ & $\frac{t+}{+t}$ & $\frac{P h W^{0}}{++}$ & Total \\
\hline$\sigma$ & 402 & 399 & 1 & 0 & 802 \\
\hline$q$ & 243 & 257 & 0 & 0 & 500 \\
\hline Total & 645 & 656 & 1 & 0 & 1302 \\
\hline
\end{tabular}

gametes out of eighty-two (which is a likely assumption), the probability that the difference between $\mathbf{F}_{2}$ and backcross is due to chance alone is 0.010 (Fisher's 'exact' method). Heterogeneity of linkage data is a common experience.

As with other spotting genes, the size of the white areas of $P h /+$ mice depends on the genetic background. In outcrosses to three inbred strains (Table 5), the $F_{1} P h /+$ mice showed widely different amounts of dorsal white.

Table 5. White areas of $\mathrm{Ph} /+$ in three outcrosses

$\begin{array}{ccccc}\begin{array}{c}\text { Outcrossed } \\ \text { to }\end{array} & \text { Extensive } & \text { Moderate } & \text { Slight } & \begin{array}{c}\text { Belly-spot } \\ \text { only }\end{array} \\ \text { A/Gr } & 9 & 1 & 0 & 0 \\ \text { C57BL/Gr } & 4 & 5 & 10 & 0 \\ \text { CBA/Gr } & 0 & 0 & 3 & 11\end{array}$

A rather more detailed analysis of the genetic background within the Patch stock was based on the following arbitrary classes:

(1) medium belly-spot;

(2) large belly-spot;

(3) large belly-spot reaching up the flanks to form an incomplete belt ( $c$ and $c^{\prime}$, Plate I);

(4) the same, but with complete belt $\left(a, a^{\prime}\right.$ and $b, b^{\prime}$, Plate I);

(5) as in (4), but white area incorporating one hind-leg;

(6) white area incorporates both hind-legs, but leaves pigmented areas on the haunches;

(7) haunches and forelegs also more or less completely white; pigment on head and shoulders only.

Wide belts sometimes enclose a pigmented island. Head-dots, so common in other types of spotting, have been completely absent. The whole pattern of spotting of 
$P h /+$ mice is best summarized as the gradual spread of a belly-spot to form a belt (sometimes with a secondary belt in the shoulder region) which then expands first posteriorly and then anteriorly. Assigning arbitrary numerical values from 1 to 7 to the seven classes, the data of Table 6 give a parent-offspring correlation of $r=0 \cdot 70 \pm 0.032$ (regression coefficient 0.86 ). This is clear evidence that the extent of white spotting in $P h /+$ mice is largely under genetic control.

Table 6. Correlation between parents and offspring as regards the extent of white spotting in $\mathrm{Ph} /+$ mice

\begin{tabular}{cccrcrrrrrrrr}
\multicolumn{10}{c}{ Midparental values } \\
Offspring & $\overbrace{1}^{1}$ & $1 \frac{1}{2}$ & 2 & $2 \frac{1}{2}$ & 3 & $3 \frac{1}{2}$ & 4 & $4 \frac{1}{2}$ & 5 & $5 \frac{1}{2}$ & 6 & Total \\
1 & 9 & 1 & 18 & 4 & 2 & & & & 1 & & & 35 \\
2 & & 1 & 19 & 2 & 8 & 5 & & 1 & & 1 & & 37 \\
3 & 1 & & 14 & 1 & 26 & 6 & 8 & 7 & 2 & & & 65 \\
4 & & & 3 & & 5 & 6 & 13 & 6 & 14 & 1 & & 48 \\
5 & & & & & 3 & 8 & 5 & 8 & 19 & 1 & 1 & 45 \\
6 & & & & & 4 & 5 & 1 & 8 & & 1 & & 19 \\
7 & & & & & & & 1 & & & & 1 & 2 \\
Total & 10 & 2 & 54 & 7 & 48 & 30 & 28 & 30 & 36 & 4 & 2 & 251
\end{tabular}

A skeletal effect of $\mathrm{Ph} /+$

A search for anomalies of the internal anatomy of $P h /+$ mice has been confined to the skeleton. Papain maceration preparations of the following bones from twenty $P h /+$ and twenty $+/+$ litter-mates have been examined: the skull and vertebral column, the girdles and the long limb bones and the sternebrae. The only anomaly discovered is that the interfrontal bone (Truslove, 1952) is often exceptionally large (Text-fig. 2; Table 7). This is probably largely due to an increase in the width of the skull in this region. As shown in Table 8, both

Table 7. Size of interfrontal. Arbitrary classes. (+) indicates an interfrontal visible from the inside, but not from the dorsal surface of the skull

$\begin{array}{ccccccc} & - & (+) & + & ++ & +++ & ++++ \\ +/+ & 3 & 3 & 1 & 12 & 1 & 0 \\ P h /+ & 0 & 1 & 0 & 4 & 5 & 10\end{array}$

Table 8. Sluull measurements, in mm., of $\mathrm{Ph} /+$ and $+1+$ mice

$\begin{array}{crrccc}\text { Measurement } & +/+ & P h /+ & t & \text { d.f. } & P \\ A & 4.81 & 5.01 & 2.85 & 19 & \sim 0.01 \\ B & 3.85 & 4.05 & 2.91 & 19 & \sim 0.01 \\ C & 15.14 & 14.83 & 3.04 & 19 & \sim 0.01\end{array}$


transverse measurements $A$ and $B$ are significantly greater in $P h /+$ than in $+/+$ mice; by contrast, the longitudinal measurement $C$ is somewhat shorter in the $P h /+$ skulls.
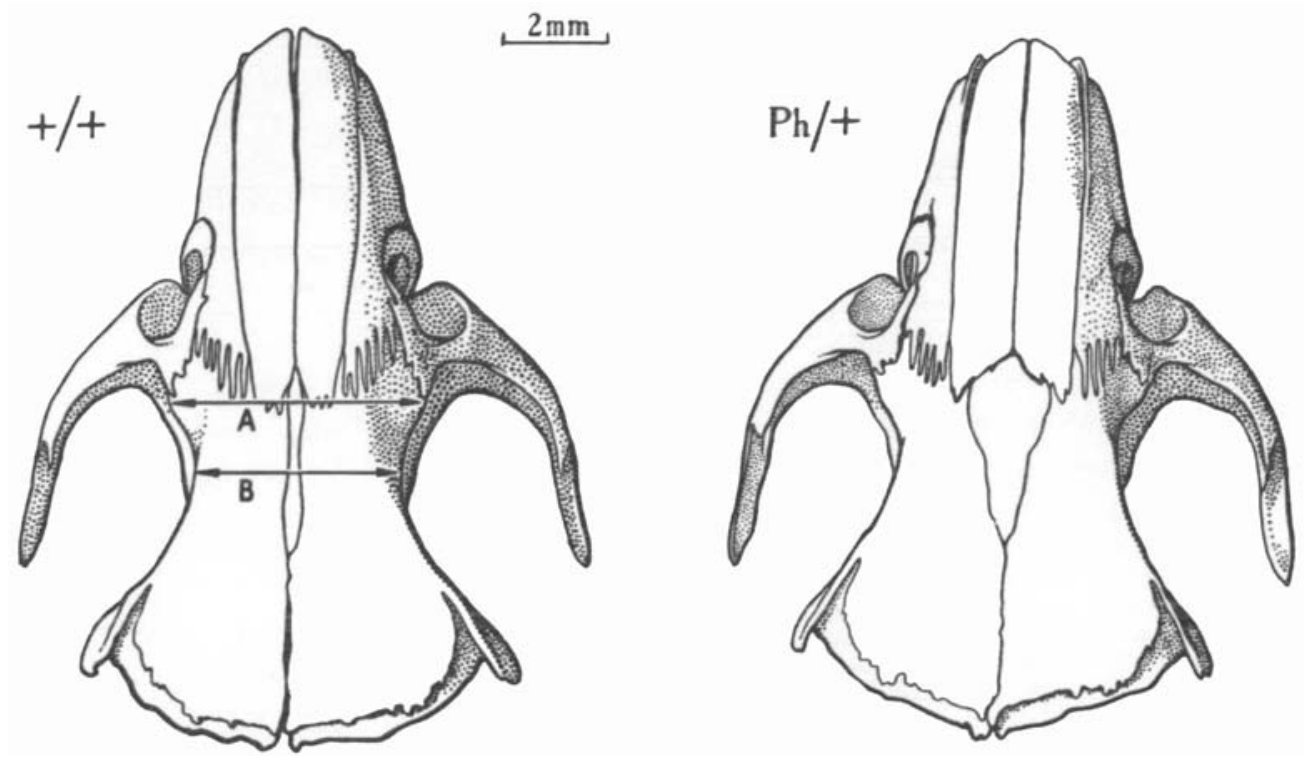

Text-fig. 2. Anterior part of the skull of a normal and a $P h /+$ litter-mate. The normal mouse has a fairly large interfrontal $(++)$ and behind it a mild expression of parted frontals. $A$ and $B$ in the normal skull indicate the position of the measurements in Table 8 ; the longitudinal measurement $C$ of that table is from the posterior margin of the basisphenoid to the nasal spine. Camera lucida drawings.

\section{The $\mathrm{Ph} / \mathrm{Ph}$ homozygote}

Late embryos. For the identification of the lethal $P h / P h$ homozygote, litters of embryos were obtained from $F_{2}$ and from backcross matings (Table 9); in the latter, the $+1+$ and $P h /+$ mice came from the same families. In the $\mathrm{F}_{2}$ matings, but not in the backcrosses, a curious monstrosity (Plates II and III) was found which is quite unlike any named entity in teratology known to us ; from the most obvious feature, the name cleft-face may be suggested. These cleft-face monsters are confined to the $\mathrm{F}_{2}$ matings and hence are obviously $P h / P h$ homozygotes. But as there are only 29 cleft-face embryos out of 336 living implantations, or $8.6 \%$, they cannot represent the whole of the $P h / P h$ class. However, the $\mathrm{F}_{2}$ matings include significantly more deciduomata (dead implantations or 'solid moles') than the backcrosses. In the $\mathrm{F}_{2}$ matings, cleft-face embryos and deciduomata together account for 235 out of 546 zygotes, or $43.0 \%$. Subtracting from this the $14.9 \%$ deciduomata found in the backcrosses (which do not include any $P h / P h$ zygotes and hence represent the basic embryonic mortality of the stock), the remainder $(28.1 \%)$ is in reasonable agreement with the $25 \%$ expectation for $P h / P h$. Hence it appears that about two-thirds of the $P h / P h$ embryos die before the 12-day 


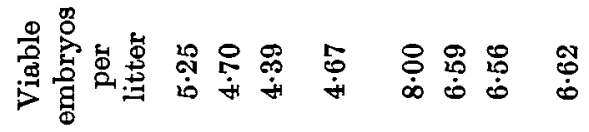

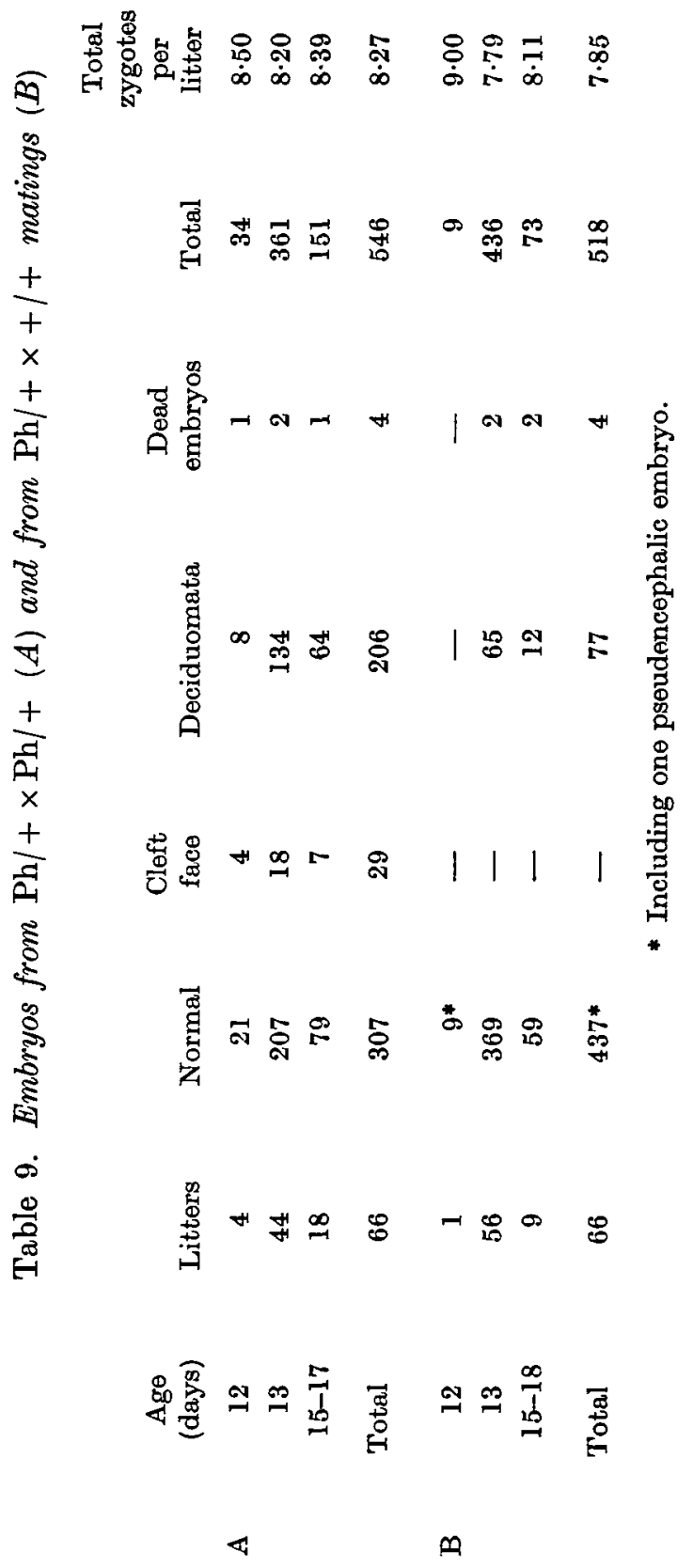


stage and appear only as deciduomata; the rest live to reach the cleft-face stage. Direct proof for this deduction will be given below.

Many 'normals', from both types of mating in Table 9, show a small bleb filled with a clear liquid on their foreheads; it is usually smaller than the one shown in Fig. 5, Plate II, and thus occurs roughly in the same position as the large bleb in $P h / P h$ embryos. The blebs are transitory and (with a single exception) confined to 12-13-day-old embryos. Out of 772 embryos of that age from thirteen other genetically mixed stocks, animals with similar blebs were found only twice. As such face-blebs occurred both in $\mathbf{F}_{2}$ and in backcross matings (Table 10), they cannot bear any relation to the $P h / P h$ genotype; but they might be a heterozygous manifestation of $P h$. However, this hypothesis is decisively contradicted by the

Table 10. Face-blebs in 12-13-day-old embryos. Same material as in Table 9, but excluding forty-five embryos which were discarded prior to the discovery of this feature.

$\begin{array}{lcccc}\text { Type of mating } & \text { Normal } & \text { Face-bleb } & \text { Total } & \text { Face-bleb \% } \\ P h /+\times P h /+ & 192 & 36 & 228 & 15 \cdot 8 \\ P h /+\times+1+ & 265 & 67 & 332 & 20 \cdot 2\end{array}$

data of Table 10. There are $228 \mathrm{~F}_{2}$ embryos, of which two-thirds, or 152, are expected to be $P h /+$; similarly, there are 332 backcross embryos, of which one-half, or 166, are expected to be $P h /+$. If face-bleb is a manifestation of the $P h /+$ genotype, it should occur with the same frequency in $P h /+$ embryos of both types of mating. The observed figures (36/152, or $23.7 \%$, versus $67 / 166$, or $40.4 \%$ ) differ highly significantly from this expectation $\left(\chi^{2}\right.$ $=10.08 ; n=1 ; P=0.0015)$. Evidently, then, face-bleb is a genetic entity whose presence in this stock is coincidental. Its distribution in the stock is not homogeneous; for instance, one family group which contributed 33 viable embryos to the $F_{2}$ and 36 to the backcross lacked face-blebs altogether; another group contributed 11 normals and 6 face-blebs to the $F_{2}$ and 45 normals and 22 face-blebs to the backcross. We reach the conclusion that face-bleb is independent of $\mathrm{Ph} /+$ with some regret, as it might have explained an otherwise somewhat enigmatic property of $P h /+$, the increased size of the interfrontal.

The cleft-face embryos are very uniform in appearance. The two halves of the nose are widely separated from each other by a cleft which is occupied by a large bleb or blister filled with a clear fluid (Fig. 4, Plate II; Fig. 6, Plate III). Similar subepidermal blebs occur in many other positions: in the face, on the fore- and hind-limbs, the nape of the neck, the shoulder region, the haunches and the thighs. Large paired blebs generally flank the neural tube down to the root of the tail (Fig. 7, Plate III ; Text-fig. 5) ; there are no blebs on the tail. The bleb fluid is clear at first, but in older foetuses (16-17 days) it tends to become haemorrhagic and such animals generally look puffed up or oedematous, particularly in the neck region. Anteriorly the neural tube is wavy and a small hole in the roof of the myelencephalon is sometimes encountered. Often the heart and parts of liver and gut are not enclosed in the body wall (ectopia cordis); this was found in 5 out of 18 embryos in one sample. The eyes may bulge considerably (Figs. 6 and 7, Plate III). Presumably as the result of the facial cleft, 15-17-day-old foetuses have a cleft palate (Fig. 6, Plate III). Two $P h / P h$ embryos had a large pollex, once on the right and once on the left (Fig. 8, Plate III); normally the pollex of the mouse is rudimentary; a similar restitution of the pollex sometimes occurs in the mutants 
Tail-short (Ts/+ ; Morgan, 1950) and luxoid (lu/lu; Forsthoefel, 1958). Cleft-face embryos progressively fall behind their normal sibs in general growth (Table 11) and apparently always die before birth.

Table 11. Crown-rump length, in mm., of normal and cleft-face embryos. Number of individuals measured in brackets

$\begin{array}{cccc}\text { Age in days } & \text { Normal (N) } & \text { Cleft-face (C) } & \text { C/N } \\ 12 & 8 \cdot 11(20) & 7 \cdot 29(4) & 0.90 \\ 13 & 9 \cdot 12(27) & 7 \cdot 75(8) & 0.85 \\ 16 & 16 \cdot 34(16) & 12.69(4) & 0.78 \\ 17 & 17.83(6) & 11.0(1) & 0.62\end{array}$

Serial sections have been prepared of two 13-day and of two 12-day cleft-face embryos (Nos. 625-626 and 642 and 644 respectively), along with four normal litter-mates (Bouin fixation, embedding by Peterf's method; sections 10 $\mu$; Ehrlich's haematoxylin and eosin). They agree with each other in the main features and can thus be described together (Text-figs. 3-6).

The superficial blebs are situated immediately under the epidermis as in 'myelencephalic' blebs (my/my) in the mouse (Bonnevie, 1934). Some of them are small and flat and not very obvious in the intact embryo. The bleb responsible for the face-cleft is smaller in the 12- than in the 13-day embryos; it continues under the epithelium of the primitive palate (Text-figs. $3 b$ and $4 c$ ) and comes to an end somewhat in front of the pituitary. In embryos 626 and 644 (but not in the others), a much smaller bleb occurs behind the pituitary between the epithelium of the epipharynx and the notochord (Text-fig. $4 a$ ); in embryo 626 it can be followed through some sixty sections $(600 \mu)$. In embryos 625,626 and 642 , anomalies occur in the cervical (and in 642 also in the thoracic and lumbar) vertebrae. The vertebral bodies are irregular in shape and tend to have bilateral double centres which sometimes are only imperfectly connected with each other. In such regions, the notochord either lies on top of the vertebral bodies (Text-fig. 5) or it is superficially embedded in them (Text-fig. 6). In embryos 626 and 642, a conspicuous and sharply defined space between neural tube and vertebral column is occupied by a tenuous web of tissue; it can be followed through many sections and its apex projects in places between the two halves of the double-centred vertebrae (Textfig. 6). Anticipating facts to be related below, this space corresponds to a large liquid-filled cavity which occurs in younger $P h / P h$ embryos; it is here evidently in the process of being filled by connective tissue.

10-11-day embryos. Six litters only are available. They are sufficient to establish the continuity between the later and the earlier manifestations of the gene, but do not justify detailed tabulation.

$P h / P h$ embryos of this stage lack superficial blebs and the cleft face. Eleven-day $\mathbf{F}_{2}$ litters include two kinds of abnormal embryos. In the first group are animals which are moderately retarded and have a wavy neural tube, particularly in the 
cervical region; in sections there are pathological features similar to some described for the later $P h / P h$ embryos. These presumably would have survived and turned into the cleft-face phenotype. The second group includes grossly retarded and highly abnormal embryos with wavy neural tubes, irregular somites and often

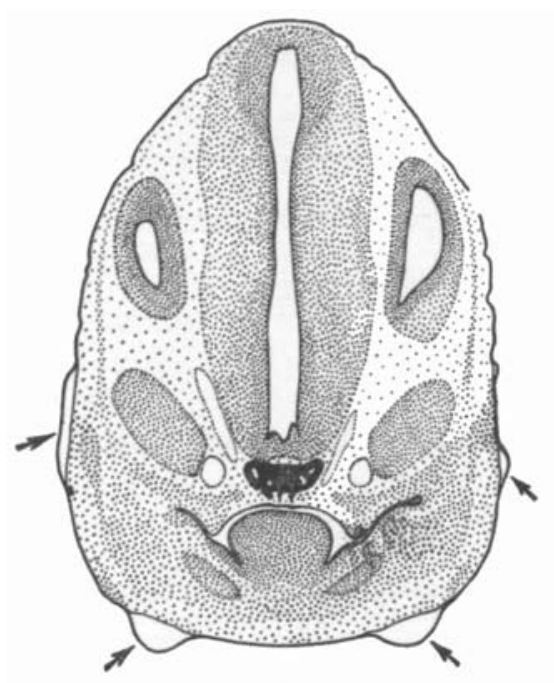

$\boldsymbol{a}$

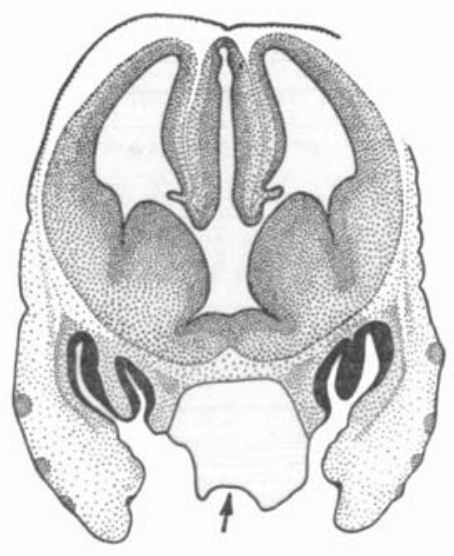

$c$

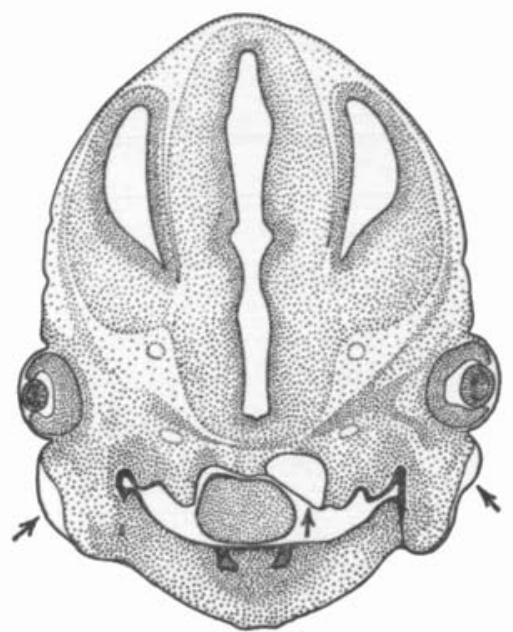

$b$

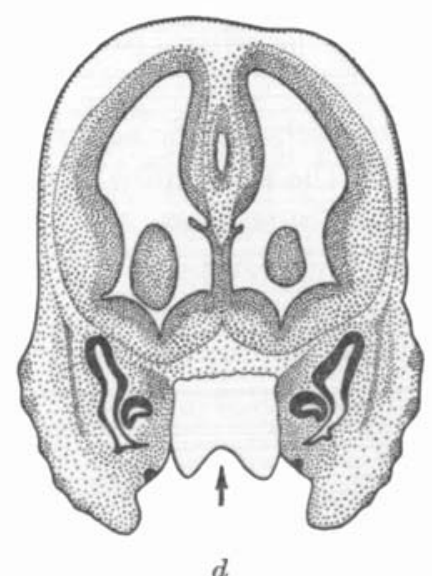

$d$

Text-fig. 3. Frontal sections through the head of a 13-day-old $P h / P h$ embryo (No. 626; C.R.L. 8.4 mm.). Projection drawings made at a magnification $\times 35$; final magnification $\times 17 \frac{1}{2}$. $a$, section through the region of the pituitary (black); $b$, through eye region; $c$ and $d$, more anteriorly still. Blebs are indicated by arrows.

an enormously inflated heart and/or pericardium; they are either dead or moribund. They closely resemble certain 9-day $P h / P h$ embryos and evidently represent the group which dies early.

From each of two 11-day litters, one normal, one mildly abnormal (presumed future cleft-face) and one grossly abnormal embryo were sectioned (the latter at 
$7 \cdot 5 \mu$ ). The two mildly abnormal embryos lack blebs under the skin. Like two of the older embryos, they have a fairly large fluid-filled cavity behind Rathke's pouch (Text-fig. $7 f$ ); this contains the notochord in its roof anteriorly ( $e$ and $f$ ),
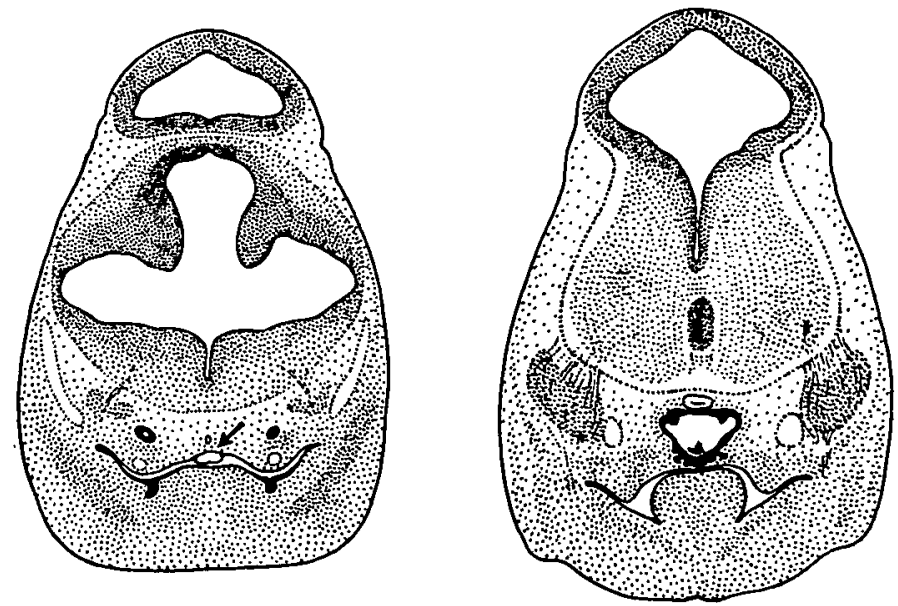

$b$

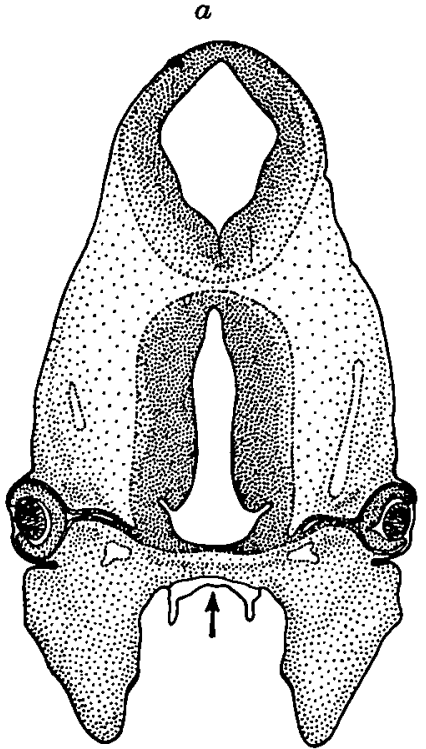

$c$

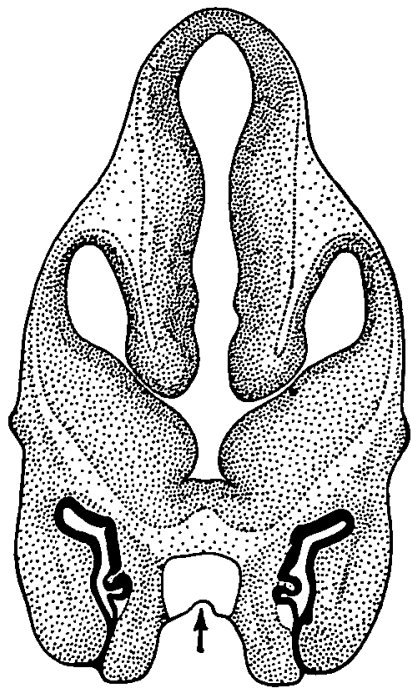

$d$

Text-fig. 4. Sections through the head of a 12-day-old $P h / P h$ embryo (No. 644;

C.R.L. $7 \cdot 4 \mathrm{~mm}$.). Magnification as in Text-fig. 3. Plane of sections about half-way between transverse and frontal. A small bleb under the epipharyngeal lining is seen in $a$; anterior to the pituitary (black in $b$ ), the large bleb responsible for the face-cleft is seen in $c$ and $d$. A small fluid-filled space is present on either side medial to the nasal cavity and underneath the evagination of Jacobson's organ in $d$.

whereas more caudally the notochord lies dorsal to the cavity $(b, c, d)$. Behind the cavity there is a roughly cylindrical space between neural tube and vertebral column with beginning ingrowth of connective tissue in one embryo, while in the other the cavity is already filled by tenuous mesenchyme. 
In embryo No. 674 a bleb has just started to form in the wide concavity between the nasal pits; evidently, the epithelium can be lifted to form a blister most easily where it covers a concave surface. Once formed, the bleb becomes a mechanical hindrance to the movement of the two halves of the nose towards the midline; in

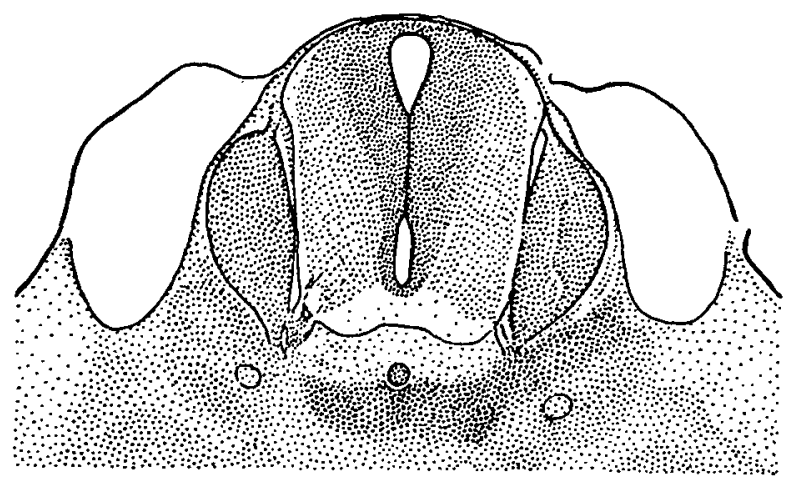

Text-fig. 5. Transverse section through the cervical region of a 13-day-old $P h / P h$ embryo (No. 626; C.R.L. $8.4 \mathrm{~mm}$.). Projection drawing made at a magnification $\times 90$; final magnification $\times 60$. Large subepidermal blebs flank the neural tube and spinal ganglia on either side, and the notochord lies dorsal to the body of the vertebra.

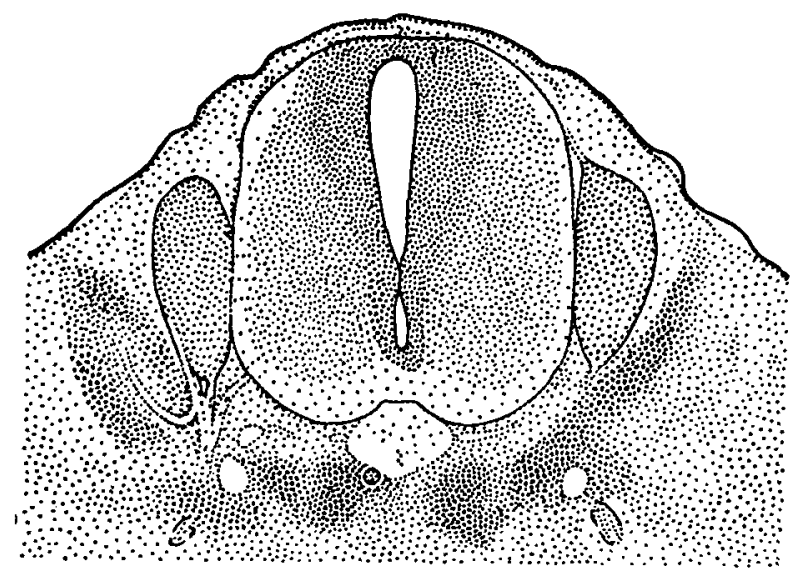

Text-fig. 6. Transverse section through the cervical region of a 12-day-old $P h / P h$ embryo (No. 642 ; C.R.L. $7.3 \mathrm{~mm}$.). Magnification as in Text.fig. 5 . The vertebral body is bilateral and the notochord is superficially embedded in the left half. A sharply defined cavity between the neural tube and the vertebral column is in the process of being filled by tenuous connective tissue.

the normal embryo, this movement has already made some progress. The cleftface phenotype found later on thus results from the prevention of movement towards the midline, not from the secondary separation of structures which had already approached one another.

Of the two highly abnormal embryos, one is certainly dead and disintegrating, 
the other probably so, with many pyknotic granules in the nervous system and elsewhere. Both are enormously blown-up with liquid. In particular the heart and great vessels are dilated to many times their normal volume; it is impossible to tell

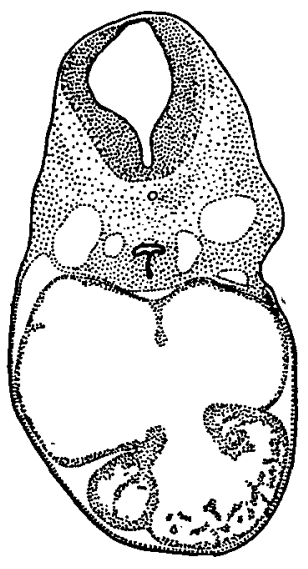

$a$

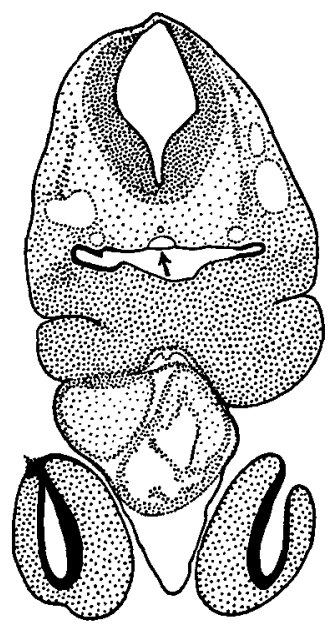

$d$
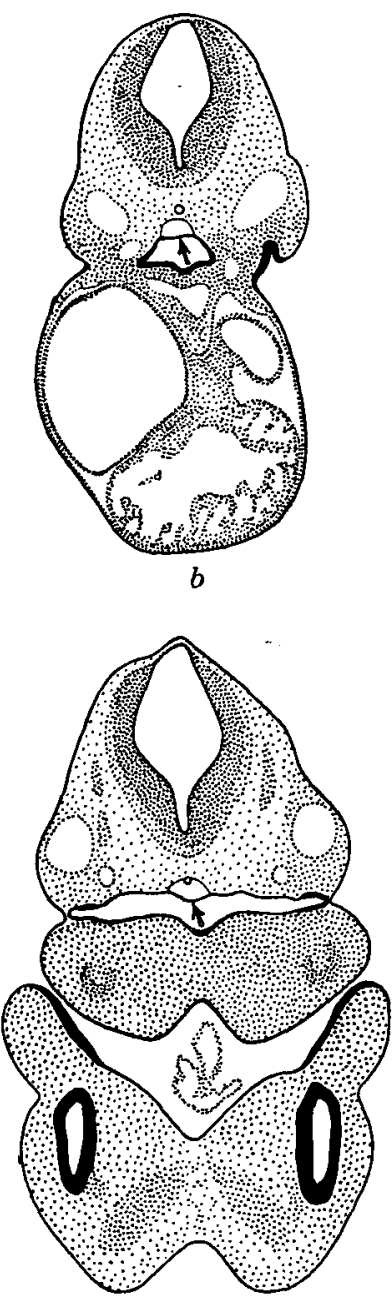

$e$
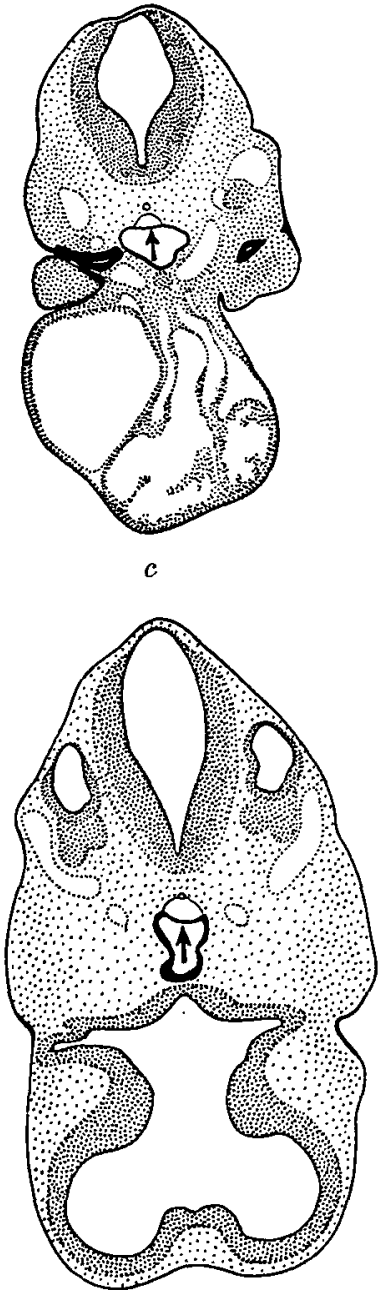

$f$

Text-fig. 7. Transverse sections through head and heart region of an 11-day-old $P h / P h$ embryo (No. 672). Projection drawings made at magnification $\times 50$; final magnification $\times 25$. $f$ passes close to the eye region, through Rathke's pouch (black) and through the ear vesicles flanking the myelencephalon; $d$ and $e$ pass through the branchial arch region and $e$ just opens the pericardium; $a, b$ and $c$ pass through more caudal parts of the heart region. Bleb indicated by arrows.

whether the blood cells are scanty by dilution only, or whether they are also absolutely reduced in numbers. The ventricular system of the brain is dilated to a lesser extent and its wall is attenuated. Waterlogging is also encountered within the tissues, and anteriorly the notochord floats by itself in a large accumulation of liquid between the brain and the foregut. In view of the dead or moribund 
condition of these embryos, one might be tempted to dismiss this fantastic 'internal drowning' as an artifact. However, very similar situations, though not quite so extreme, are encountered in 9-day $P h / P h$ embryos which are undoubtedly alive.

9-day embryos. Eight out of eighteen $\mathrm{F}_{2}$ litters of this stage (Table 12) were collected in 1952 ; the number of deciduomata in this group $(16.8 \%)$ is roughly the same as the background mortality in Table $9(14.9 \%)$. The rest of the material was collected in 1956 when the stock happened to be fairly inbred, and, as a consequence, had a much higher embryonic mortality; this is, however, virtually the same in the $\mathrm{F}_{2}$ and backcross data ( 38.1 and $39.8 \%$ respectively); hence, at the 9 -day stage the $P h / P h$ embryos are still alive. This is borne out by direct observation.

\begin{tabular}{|c|c|c|c|c|c|c|c|c|}
\hline Year & Litters & Normal & $P h / P h$ & $?$ & $\begin{array}{l}\text { Total } \\
\text { living } \\
\text { embryos }\end{array}$ & $\begin{array}{c}\text { Decidu- } \\
\text { omata }\end{array}$ & $\begin{array}{l}\text { Grand } \\
\text { total }\end{array}$ & $\begin{array}{l}\text { Decidu- } \\
\text { omata \% }\end{array}$ \\
\hline 1952 & 8 & 39 & 12 & 3 & 54 & 11 & 65 & 16.8 \\
\hline 1956 & 10 & 46 & 8 & 6 & 60 & 37 & 97 & $38 \cdot 1$ \\
\hline Total & 18 & 85 & 20 & 9 & 114 & 48 & 162 & - \\
\hline 1956 & 14 & 71 & 一 & - & 71 & 47 & 118 & $39 \cdot 8$ \\
\hline
\end{tabular}

Nearly all the abnormal $(P h / P h)$ embryos of this stage can be distinguished from their normal litter-mates by external inspection. They have wavy neural tubes similar to those found in later stages. More severely affected individuals have irregularities of the somites, and the most abnormal ones are inflated with enormous hearts, or hearts of about normal size inside a huge pericardium. Depending on the degree of abnormality, $P h / P h$ embryos are retarded to a greater or lesser extent as compared with their normal litter-mates. The typical normal 9-day embryo is U-shaped and has just completed its turning movement. Corresponding $P h / P h$ embryos have often completed the turning movement at both ends of the body, but not yet in the middle, which is thus still more or less widely open; evidently, this delay in the closure of the ventral body wall together with an enlargement of heart or pericardium is the cause of the ectopia cordis mentioned in an earlier section. In a few younger litters of this group, in which the normal embryos have not yet completed their turning movement, $P h / P h$ embryos are less easy to recognize by external inspection, and classification must rely mainly or entirely on the sectioned material.

All 9-day $\mathrm{F}_{2}$ embryos have been serially sectioned (at $7 \cdot 5 \mu$ ) except four normals and one $P h / P h$ embryo from a litter in the 1952 group. Twenty out of 105 fully classified embryos have been identified as $P h / P h$ homozygotes, in reasonable agreement with the $3: 1$ expectation $\left(\chi^{2}=1.98 ; n=1 ; P=0.16\right.$ approx.). Five out of nine unclassified embryos were damaged, and another specimen was a very retarded (pre-somite) embryo. Two of the three remaining doubtful specimens 
have been classified as 'probably $P h / P h$ '. The agreement with the Mendelian expectation is thus quite satisfactory. No abnormal embryos resembling the $P h / P h$ class have been observed in the backcross matings. It has not been deemed necessary to section these seventy-one embryos.

All 9-day $P h / P h$ embryos examined had accumulations of a clear liquid flanking the notochord (compare Figs. 9 and 10 with 11 and 12 and with 13 and 14, Plate IV). In the older embryos of this group, the liquid is more often found in the anterior parts of the trunk up to, and including, the region of the myelencephalon; in younger ones it tends to be more marked posteriorly. The amount of liquid is variable, but, almost without exception, $P h / P h$ embryos can be distinguished from their normal sibs by this feature alone. In some $P h / P h$ embryos, the heart and the whole vascular system is dilated (Text-fig. 8), sometimes to an extraordinary
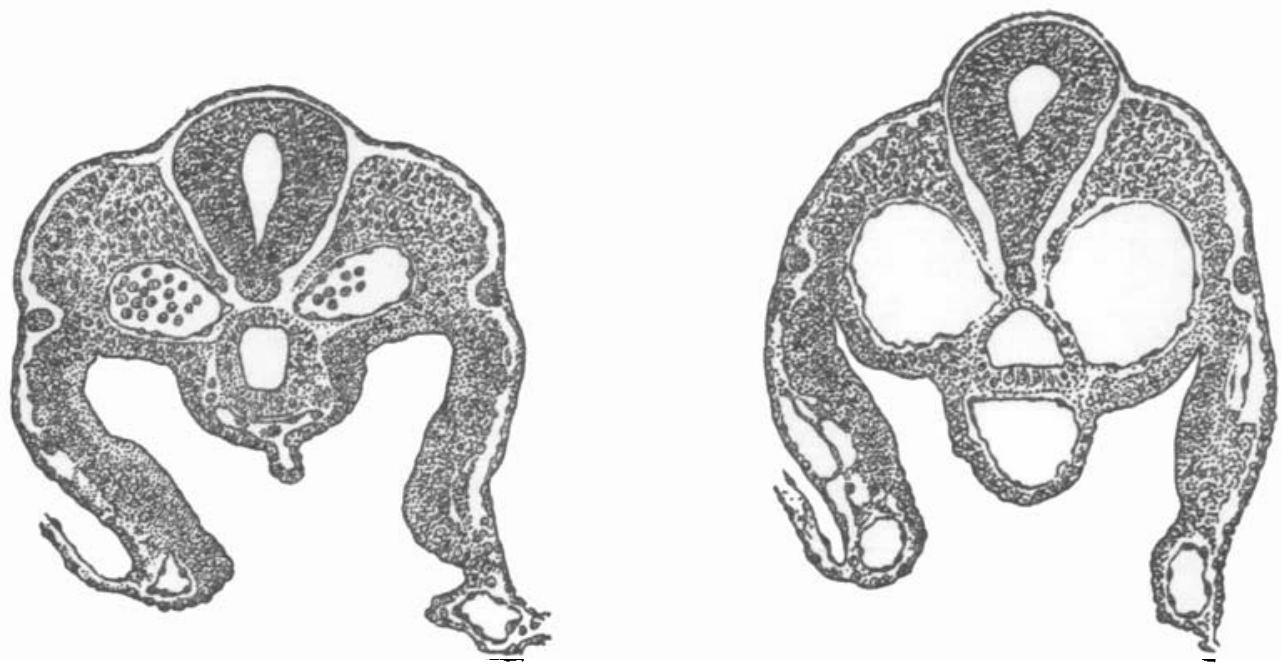

Text-fig. 8. Transverse sections through the trunk region of a normal and a $P h / P h$ embryo (litter-mates, 9 days old). Note the dilation of the dorsal aortae and of the common umbilical artery. Projection drawings made at magnification $\times 200$; final magnification $\times 100$.

extent; bulging blood-vessels may leave fairly deep impressions on the surface of the neural tube and are responsible for some, at least, of the irregularities visible externally. In some cases, the circulatory system is not much dilated, but large quantities of liquid are found inside the pericardium; a rather mild case of this kind is shown in Fig. 11, Plate IV. Particularly in younger stages, i.e. before the turning movement is complete, some $P h / P h$ embryos have large subepidermal blebs flanking the neural tube; in the embryo shown in Text-fig. 9, which is still completely unturned, each of the two long blebs is cut twice; liquid also penetrates between the somites, and it appears that the somite irregularities found in all more severely affected embryos must be ascribed to this fact. Subepidermal blebs in other positions are sometimes encountered in badly affected embryos, and there may be oedema of the mesenchyme. 
Evidently the more severely affected $P h / P h$ embryos die soon after the ninth day, and only the more mildly affected individuals survive to reach the cleft-face stage; these, at the 9-day stage, have some para-chordal liquid, but are otherwise comparatively normal.

8-day embryos. Even more than those of the preceding group, 8-day embryos of the present material differ considerably in the stage of development which they have reached, both within and between litters. All of them have been serially sectioned (at $7.5 \mu$ ) within their membranes and within the decidua. They all come from $P h /+\times P h /+$ matings.

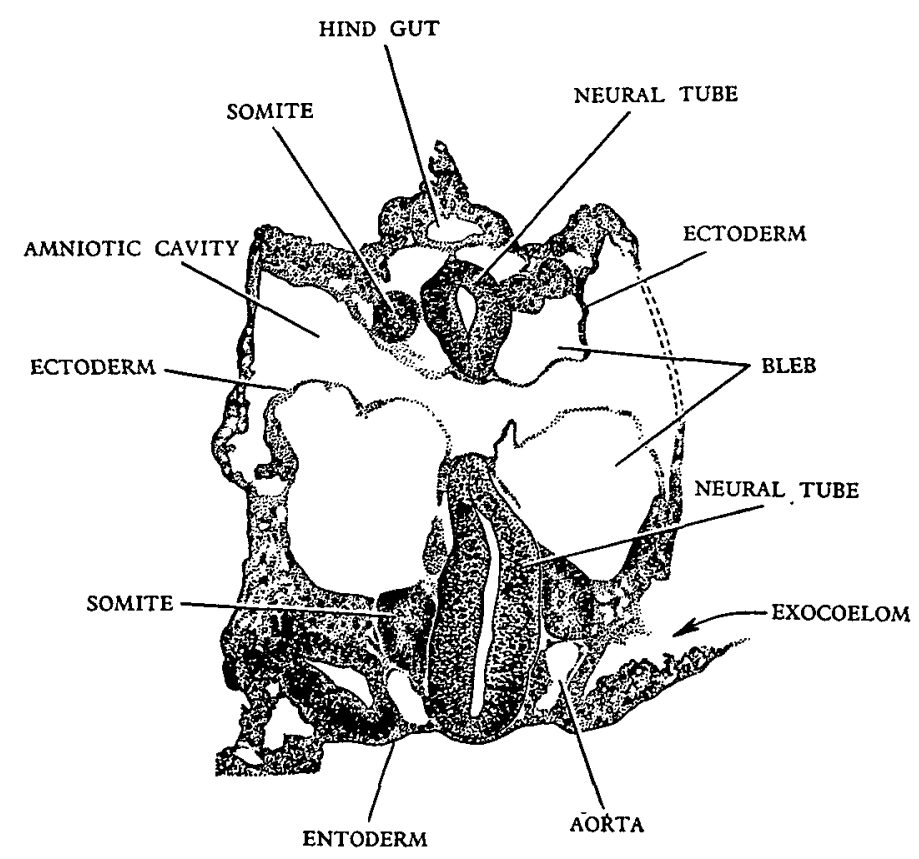

Text-fig. 9. Unturned $P h / P h$ embryo, 9 days old, with large blebs flanking the neural tube. Further explanation in the text. Tracing from microphotograph, magnification $\times 180$; final magnification $\times 90$.

One litter of ten embryos consisted entirely of early somite stages; another litter, of six embryos, included three individuals in the early somite stage and three pre-somite embryos. The thirteen early somite embryos have somite counts ranging from 3 to 10 . In some of them the allantois has made contact with the ectoplacental cone, in others it has not. The nominal age of this group may be given as approximately $8 \frac{1}{2}$ days. We have failed to discover any abnormalities in this group which can be ascribed to the $P h / P h$ genotype.* On a $3: 1$ expectation, the probability of finding thirteen normals and no $P h / P h$ is 0.0238 . It is thus improb-

* In two embryos, maternal blood was present in the exocoelom, the ectoplacental cavity and/or the amniotic cavity. It is virtually certain that this was due to an injury inadvertently inflicted on the mother immediately before she was killed. In order to save those females of the 8-day group which had failed to become pregnant despite their vaginal plugs, all of them 
able that this sample failed to include any $P h / P h$ embryos. If some such embryos were, in fact, present, they were either still phenotypically normal or, if they were not, their abnormalities were of a kind which we have failed to recognize. Needless to say, we have not discovered abnormalities in the twenty-five still earlier (pre-somite) embryos which we have examined.

The essential abnormality of the $P h / P h$ embryo is an increase of its water content (hydrops). This develops between the 8- and 9-day stage. Abnormal accumulations of liquid are found flanking the notochord first posteriorly and later anteriorly. To a varying extent, excess liquid is also found in the circulation, in the pericardium, under the epidermis and within the tissues. The more extremely affected embryos die round about the tenth day. The survivors regularly develop a subepidermal bleb on the concavity of the primitive palate which becomes the mechanical cause for the facial cleft.

The more extreme manifestations of $P h / P h$ show at a glance that the total water content of the embryo is greatly increased and that the excess liquid must thus have come from outside the embryo. Whether it enters the embryo via the allantois, or whether it is derived from the amniotic cavity or from the extraembryonic coelom, must remain an open question. It is, however, clear that the total quantity of excess liquid continues to increase and that the $P h / P h$ embryo remains leaky for some considerable time.

\section{DISCUSSION}

The genes for $P h$ and $W$ are located within $0.077 \mathrm{cM}$. of each other. What is the probability that a new spotting gene should be located so close to a known one? Casting the net very widely and including some rather doubtful entities, there are about fifteen known loci in the mouse which can be regarded as 'spotting genes'. The total map length of $\pm 0.1 \mathrm{cM}$. round these fifteen loci is $3 \cdot 0 \mathrm{cM}$. According to Carter (1955), the total genetic map length of the mouse amounts to $16 \cdot 2 \pm 3 \cdot 5 \mathrm{M}$. Hence, as a first approximation, the probability of a new spotting gene being located within $0.1 \mathrm{cM}$. of a known one is $3 / 1620$, or 0.00185 . Without going into refinements, it is thus clear that the close proximity of $P h$ and $W$ is probably not a chance event; it thus becomes necessary to compare their effects in more detail by reference to Table 13 .

The question to be answered is whether $P h$ and $W$ are non-complementary (i.e. alleles, though, of course, with different mutational sites), or whether they are complementary to each other like the Drosophila doublets which were mentioned in the Introduction. This question is more easily asked than answered. In the case of two recessive genes, the mutant phenotype of the compound $a^{1} / a^{2}$ is generally taken as the criterion for functional allelism. No such criterion is at

had their uteri palpated for pregnancy just before they were killed. This practice was later discontinued when these two (and other) embryos showed the unforeseen damage thus caused.

It is very probable that similar lesions of the trophoblast in putative hydrocephalus-1 embryos which Bonnevie (1945) described as an early manifestation of that gene were, in fact, traumatic as explained above. 
present available in the case of dominant genes such as $P h$ and $W$. We will now discuss each item of Table 13 in more detail.

Table 13. The main effects of the $\mathrm{Ph}$ and $\mathrm{W}$ loci

$\begin{array}{llcccccc} & & P h /+ & P h / P h & W /+ & W / W & W^{v} /+ & W^{v} / W^{v} \\ \text { 1. } & \text { Spotting } & + & ? & + & +++ & + & +++ \\ \text { 2. } & \text { Dilution } & (+) & ? & - & - & + & - \\ \text { 3. } & \text { Anaemia } & (+) & ? & - & +++ & + & ++ \\ \text { 4. } & \text { Sterility } & - & - & - & + & - & + \\ \text { 5. } & \text { Hydrops } & - & + & - & - & - & -\end{array}$

(1) Spotting. Most of the spotting of $P h /+$ mice consists of a sharply defined ventral area with or without belt. However, some roan or variegated spotting like that of $W /+$ and $W v /+$ may occur, particularly in the belt region and/or the shoulders. How much weight should be given to the interaction of the genes in the $P h+1+W^{v}$ double heterozygote is somewhat problematical. Interactions between non-allelic spotting genes (as in the black-eyed white $W /+; s / s$ mouse) have been known for a long time; and $P h$ itself also interacts rather strikingly with $s / s, b t / b t$ and $M i^{w h} /+$. But this does not exclude the possibility that the interaction with $W^{v}$ might be specific.

Could the phenotype of the $P h+1+W^{v}$ mouse be regarded as equivalent to that of a compound $P h / W^{v}$ if the two entities are alleles? $W^{v} / W^{v}$ mice are blackeyed whites but their ears are sometimes a little sooty. $P h / P h$ embryos have pigmented eyes (Plates II and III), and presumably, if they lived to grow hair, they would be whiter than the $P h /+$ heterozygote. If they are potential black-eyed whites, the phenotype of $P h+1+W^{v}$ would be partly complementary. If, on the other hand, $P h / P h$ is potentially a white mouse with a pigmented head, $P h$ and $W^{v}$ could be regarded as non-complementary, with $P h$ dominant over $W^{v}$. The question must remain open until the potential fur colour of various regions of $P h / P h$ embryos has been established by transplantation experiments. That such experiments are practicable has been shown by Rawles (1947) in normal 8-12-day mouse embryos, and by Auerbach (1954) in the case of the Splotch $(S p / S p)$ homozygote which dies at the beginning of the thirteenth day of development.

(2) Dilution. Dilution of the fur pigmentation in the pigmented areas occurs in $W^{v} /+$, but not in $W /+$ heterozygotes. By itself, $P h /+$ does not dilute fur pigmentation in agouti and non-agouti $(a / a)$ mice as judged by eye. However, the $P h$ gene seems to interact with $W^{v}$ in this respect. In $P h+/+W^{v}$ mice, the pigmented areas of the head are a little paler than in $W^{v} /+$ animals. It is difficult to be certain whether this is brought about by a general dilution of hair pigmentation or by an admixture of white hairs to the fur; in either case, an interaction is indicated as $P h /+$ by itself has neither effect.

(3) Anaemia. As first shown by one of us (Grüneberg, 1939, 1942) and subsequently confirmed by many other authors, $W / W, W / W^{v}$ and $W^{v} / W^{v}$ mice suffer 
from a macrocytic anaemia; in a very mild form this is also present in $W \%+$, but not in $W /+$ mice. For purposes of comparison, we have examined 13-14day-old $P h /+$ mice although, in view of the haematological normality of the $W /+$ heterozygote, only positive findings would be decisive. Haemoglobin was estimated by means of the M.R.C. grey-wedge photometer; the volume of packed cells was determined with a Hawksley micro-haematocrit centrifuge; and cell counts were made in the usual way in an improved Neubauer counting chamber.

Comparing $++1++$ with $P h+1++$ mice (Table 14), it is obvious that $P h$ by itself has no appreciable effect on the red-blood picture of 13-14-day-old mice; however, slight effects, or effects at other stages of development, are not excluded. The situation is less clear on the right side of Table 14. $P h+/+W^{v}$ mice have

Table 14. The red-blood picture in 13-14-day-old animals. Averages of fifteen animals in each case. Animals in the first two and in the last two columns are litter-mates. In two instances in the last two columns, two animals of either lind were taken from the same litter; in view of intra-litter correlations, the mean values of the two pairs have been used in significance tests so that there are only twelve degrees of freedom in $\mathrm{t}$ tests

\section{$\mathrm{Hb}$ (g./100 ml.) \\ R.B.C. per $\mathrm{mm}^{3}$ \\ Haematocrit \%}

Mean corpuscular volume in $\mu^{3}$

Mean $\mathrm{Hb}$ concentration \%

Mean $\mathrm{Hb}$ content in $\gamma \gamma$

$++/++$
$11 \cdot 0$
$5,628,000$
$33 \cdot 7$
$60 \cdot 9$
$32 \cdot 6$
$19 \cdot 6$

$19 \cdot 6$

$P h+/++$
$10 \cdot 8$
$5,535,000$
$32 \cdot 7$
$59 \cdot 3$
$33 \cdot 0$
$19 \cdot 6$

$++/+W^{v}$
$10 \cdot 0$
$4,629,000$
$30 \cdot 7$
$66 \cdot 9$
$32 \cdot 5$
$21 \cdot 7$
$P h+1+W^{v}$
$9 \cdot 7$
$4,267,000$
$29 \cdot 6$
$69 \cdot 4$
$33 \cdot 0$
$22 \cdot 9$

rather lower blood counts (R.B.C.) than their $++1+W^{v}$ litter-mates; the difference is, however, barely significant $(t=1 \cdot 835 ; n=12 ; P=0.09$; considering that the difference is in the expected direction, $P=0 \cdot 045)$, and the differences as regards $\mathrm{Hb}$ and haematocrit are not significant $(t=1 \cdot 11$ and $1 \cdot 50$ respectively). Both $W v /+$ genotypes show a mild macrocytic anaemia as compared with $+1+$ mice in conformity with previous findings (Grüneberg, 1942; and others). But the red cells of $P h+1+W^{v}$ are not significantly more macrocytic than those of $++1+W^{v}$ mice $(t=0.94 ; n=12)$ which might have been expected in the case of a specific interaction. The increased anaemia of the double heterozygotes, if real, is thus certainly slight. The possibility must also be considered that their low cell count may be an expression of their retardation rather than its cause.

The $P h / P h$ embryo presents almost insuperable difficulties to the application of standard haematological techniques. Bouin-fixed sectioned material stained with H. \& E. is not suitable for the detection of anomalies of the red-blood picture except the very coarsest ones. Repeatedly we have thought we had discovered cytological differences in the embryonic red blood cells, but we do not regard the 
question as settled either way. A fresh start with more suitable techniques will thus be required.

(4) Sterility. $W / W, W / W^{v}$ and $W^{v} / W^{v}$ mice are sterile or nearly so. As shown by Mintz \& Russell (1957), their primordial germ cells form normally at 8 days, but subsequently they fail to multiply and are retarded in their migration from the yolk-sac to the germinal ridges. Using the same histological technique, we have examined two normal and two $P h / P h$ 10-day embryos from an $\mathrm{F}_{2}$-type litter. Normal and $P h / P h$ embryos had similar numbers of primordial germ cells, and though in the absence of complete counts smaller differences cannot be excluded, there is certainly no prima facie case indicating sterility in the $P h / P h$ mouse if it survived to breeding age.

(5) Hydrops. No disturbances of embryonic liquids comparable to those found in $P h / P h$ homozygotes have been described for $W / W$ or $W^{v} / W^{v}$ embryos. Obviously, none severe enough to be lethal or to lead to cleft-face are present. If mild hydrops perhaps occurs in 9-10-day-old $W / W$ etc. embryos, it might be detectable in the material of Mintz \& Russell (1957). Disturbances of liquid balance (oedema, blebs) are often encountered in amphibian embryos which have been subjected to surgical interference; so perhaps these disturbances in $P h / P h$ embryos (and those in 'myelencephalic' blebs, my/my; Bonnevie, 1934) may be comparatively unspecific and rather far removed from the primary gene action.

While, at present, it is not possible to state with confidence that the interaction between two dominant genes is specific, it may be possible to state with confidence that it is not. If, for each gene separately, developmental studies have established a pedigree of causes of the pleiotropic effects, an interaction which involves remote gene effects is clearly not specific.

Unfortunately, despite the great effort by many workers which has gone into the analysis of the $W$-series, the causal connexions between the effects on pigmentation, blood and germ cells have not yet been clarified. The same applies to the pleiotropic effects of $P h$, as indeed to a long series of genes in the mouse which involve pigmentation along with a variety of other organ systems.

The facts that $P h / P h$ mice are potentially fertile while $W / W$ and $W^{v} / W^{v}$ mice are sterile, and that $P h / P h$ embryos are hydropic while $W / W$ and $W^{v} / W^{v}$ are not, cannot be evaluated until the position of these effects in the respective pedigrees of causes is known. A discrepancy of secondary effects is obviously of less weight than a discrepancy in fundamentals.

The relationship between $P h$ and the $W$-series thus remains problematical at present. The data presented are clearly not a strong case for the existence of a specific (allelic) interaction between the genes, but they do not rule it out. Perhaps the strongest indirect evidence against a specific interaction is the existence of the gene for Steel ( $S l$; Sarvella \& Russell, 1956; Bennett, 1956) in the mouse. This gene is a very close mimic of $W^{v}$, both in the heterozygous and in the homozygous condition; in the $S l /+$ mouse, there is spotting, dilution of coat colour and a mild macrocytic anaemia; $S l / S l$ is potentially a black-eyed white, it has an extreme macrocytic anaemia which usually kills it before birth, and it has a clear involve- 
ment of the primordial germ cells. The close similarity between $S l$ and $W^{\circ}$ (which segregate independently of each other) is evidence for a close causal connexion between the pleiotropic effects; hence a gene which interferes with the hypothetical pedigree of causes near its root will produce the full triad. If this reasoning is valid, the marked differences between $P h$ and the $W$-series suggest. that they are not alleles, but a gene doublet with complementary action.

\section{SUMMARY}

(1) In heterozygous condition, the gene for Patch (symbol $P h$ ) produces spotting with sharply defined pigmented and white areas. The extent of the spotting is under the control of the genetic background.

(2) The $P h / P h$ homozygote is inviable and dies before birth. In 9-day embryos, clear liquid is found flanking the notochord; in addition, there may be excessive amounts of liquid in the pericardium, the circulation, the tissues, and under the epidermis. The more extremely affected $P h / P h$ embryos die at about 10 days. About one-third survive to later stages of pregnancy. Such 'cleft-face' embryos have a large bleb of liquid in the middle of the face which interferes mechanically with the formative movements of the nose and palate, and many subepidermal blebs elsewhere.

(3) $P h$ is closely linked to the gene for dominant spotting with macrocytic anaemia $\left(W, W^{v}\right)$ in linkage group III, the crossover percentage being 0.077 . There is a striking interaction in the double heterozygote $P h+1+W^{v}$ which is almost white, but nearly equally striking interactions occur with other spotting genes $\left(s, b t\right.$ and $\left.M i^{w h}\right)$.

(4) By itself, $P h$ has no detectable effect on the coat colour, but in the double heterozygote with $W^{v}$, it slightly increases the dilution effect of the latter in the regions which remain pigmented. Similarly, $P h$ by itself has no appreciable effect on the red-blood picture of 13-14-day-old animals, but in the double heterozygote with $W^{v}$, it probably slightly increases the mild macrocytic anaemia produced by that gene. It remains unknown whether the $P h / P h$ homozygote has an effect on the blood. Unlike $W / W$ and $W^{v} / W^{v}, P h / P h$ has no appreciable effect on the primordial germ cells.

(5) The relationship between $P h$ and the $W$-series is discussed.

The authors are deeply indebted to Dr W. F. B. Cuthbertson (Glaxo Laboratories, Greenford, Middlesex) for the gift of the original Patch animals. Dr A. G. Searle kindly looked after the stock during the summer of 1952. The microscopic preparations were made by Miss Hermingard Bartels-Walbeck and by Miss Renate Kühne. The photographs of Plate I were taken by the late Mr A. J. E. Munday and the microphotographs of Plate IV by Miss Heide Schulze. Mr A. J. Lee prepared the drawings of Plates II and III and assisted with many of the text-figures. The work described in this paper was supported by a grant from the Rockefeller Foundation which is gratefully acknowledged. 


\section{REFERENCES}

AUerbach, R. (1954). Analysis of the developmental effects of a lethal mutation in the house mouse. J. exp. Zool. 127, 305-330.

BenneTt, D. (1956). Developmental analysis of a mutation with pleiotropic effects in the mouse. J. Morph. 98, 199-234.

BonNevie, K. (1934). Embryological analysis of gene manifestation in Little and Bagg's abnormal mouse tribe. J. exp. Zool. 67, 443-520.

BonNevie, K. (1945). Hereditary hydrocephalus in the house mouse. III. Manifestation of the $h y$-mutation in embryos 9-11 days old, and younger. Skr. norske VidenskAkad., $I$. Mat.-Naturv. Kl., 1944, No. 10, pp. 60.

Carter, T. C. (1955). The estimation of total genetical map lengths from linkage test data. J. Genet. 53, 21-28.

DunN, L. C. (1956). Analysis of a complex gene in the mouse. Cold Spr. Harb. Symp. quant. Biol. 21, 187-95.

FonsthoEFEL, P. F. (1958). The skeletal effects of the luxoid gene in the mouse, including its interactions with the luxate gene. J. Morph. 102, 247-287.

GRÜNEBERG, H. (1937). Gene doublets as evidence for adjacent small duplications in Drosophila. Nature, Lond., 140, 932.

GRÜNEBERG, H. (1939). Inherited macrocytic anemias in the house mouse. Genetics, 24, $777-810$.

GRüNEBERG, H. (1942). Inherited macrocytic anaemias in the house mouse. II. Dominance relationships. J. Genet. 43, 285-293.

MiNTz, B., \& RUSSELL, E. S. (1957). Gene-induced embryological modifications of primordial germ cells in the mouse. J. exp. Zool. 134, 207-238.

Morgan, W. C. (1950). A new tail-short mutation in the mouse whose lethal effects are conditioned by the residual genotype. J. Hered., 41, 208-215.

RAwLES, M. E. (1947). Origin of pigment cells from the neural crest in the mouse embryo. Physiol. Zool., 20, 248-266.

Sarvelia, P. A. \& Russeld, L. B. (1956). Steel, a new dominant gene in the house mouse with effects on coat pigment and blood. J. Hered. 47, 123-8.

Truslove, G. M. (1952). Genetical studies on the skeleton of the mouse. V. 'Interfrontal' and 'parted frontals'. J. Genet., 51, 115-22. 


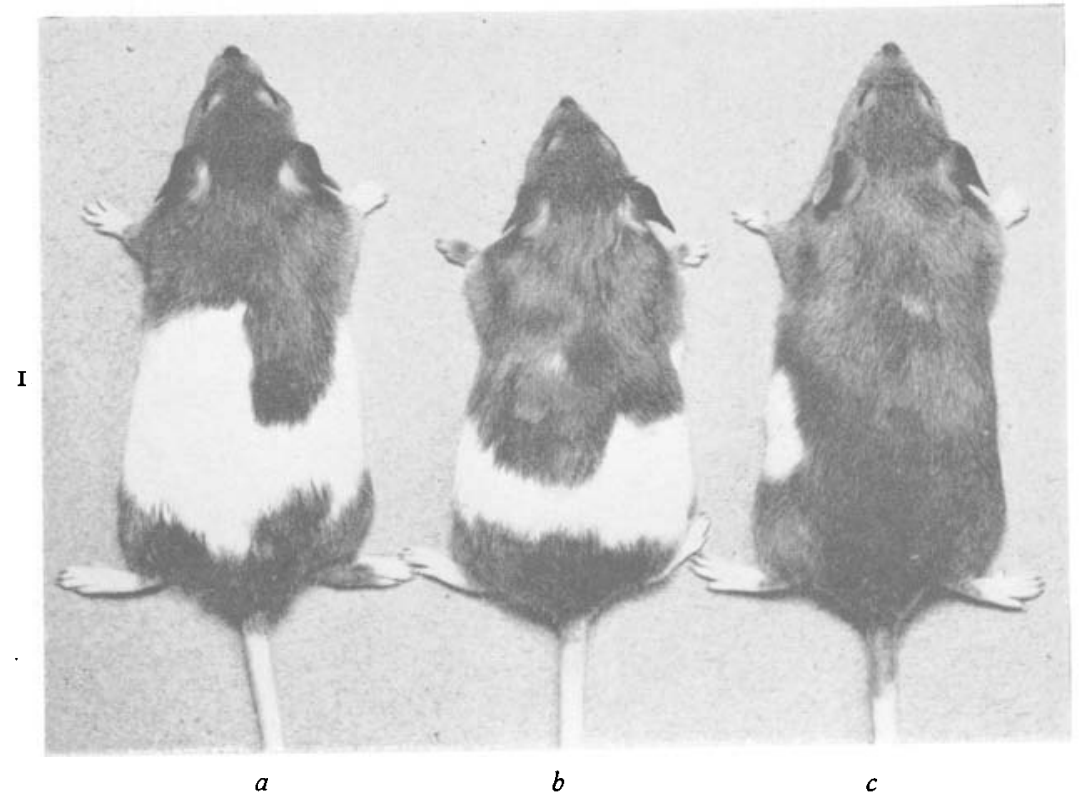

2.

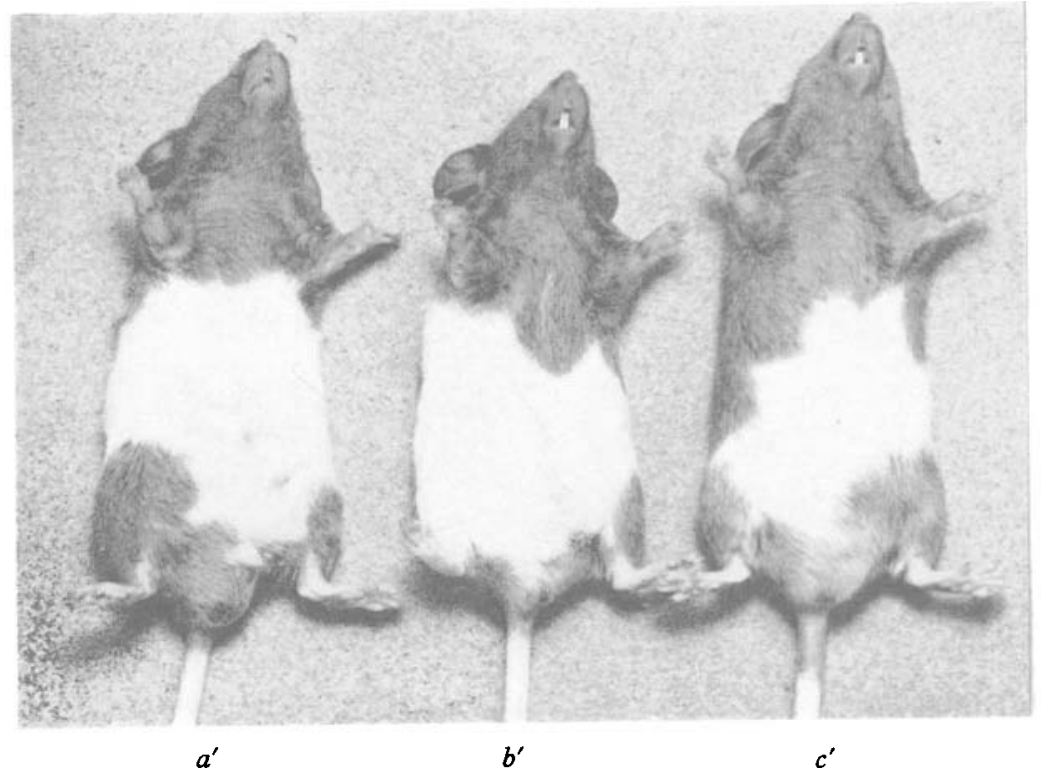

Dorsal and ventral views of three $P h /+$ heterozygotes.

H. (:RÜNEBERG AND G. M. TRUSLOVE

(F'ucing 1.90$)$ 
3.
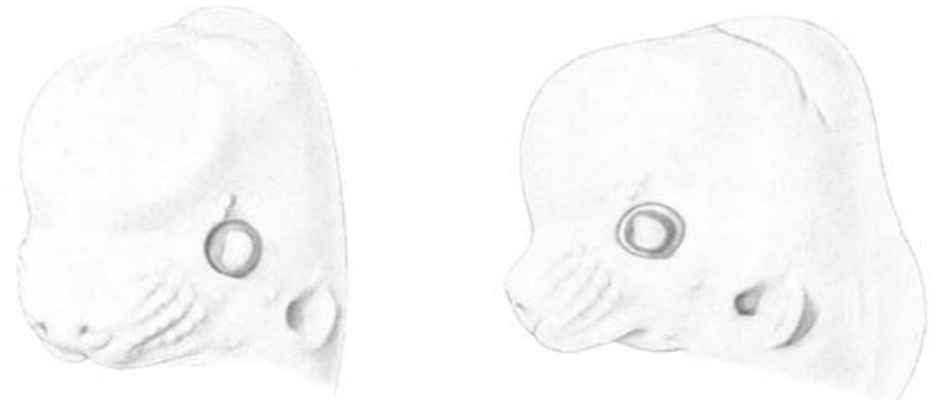

4 .
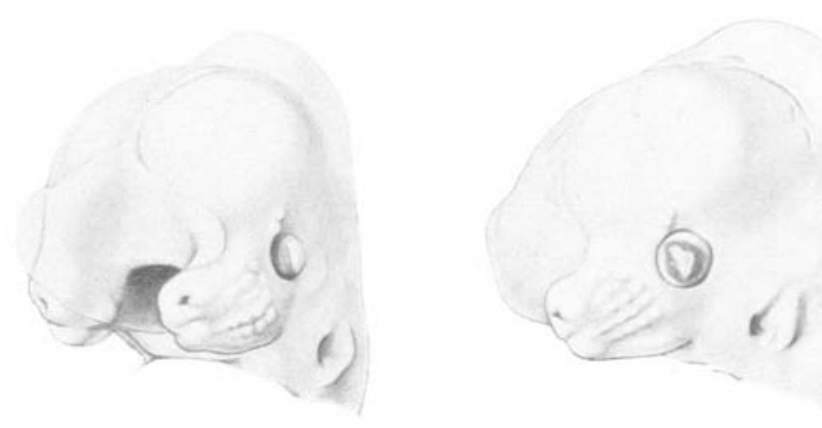

5.
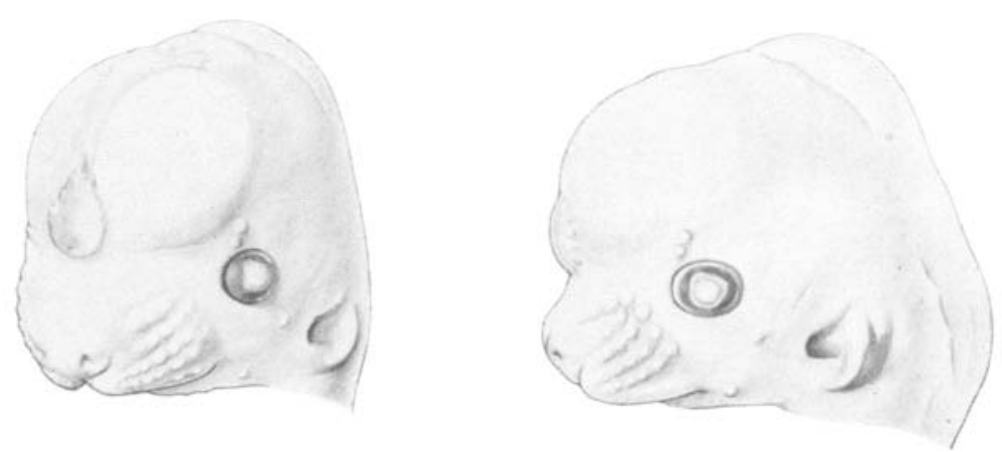

Heads of 13-day embryos. Fig. 3, normal; Fig. 4, cleft-face $(P h / P h)$; and Fig. 5, normal with face bleb.

H. GRÜNEBERG AND G. M. TRUSLOVE 


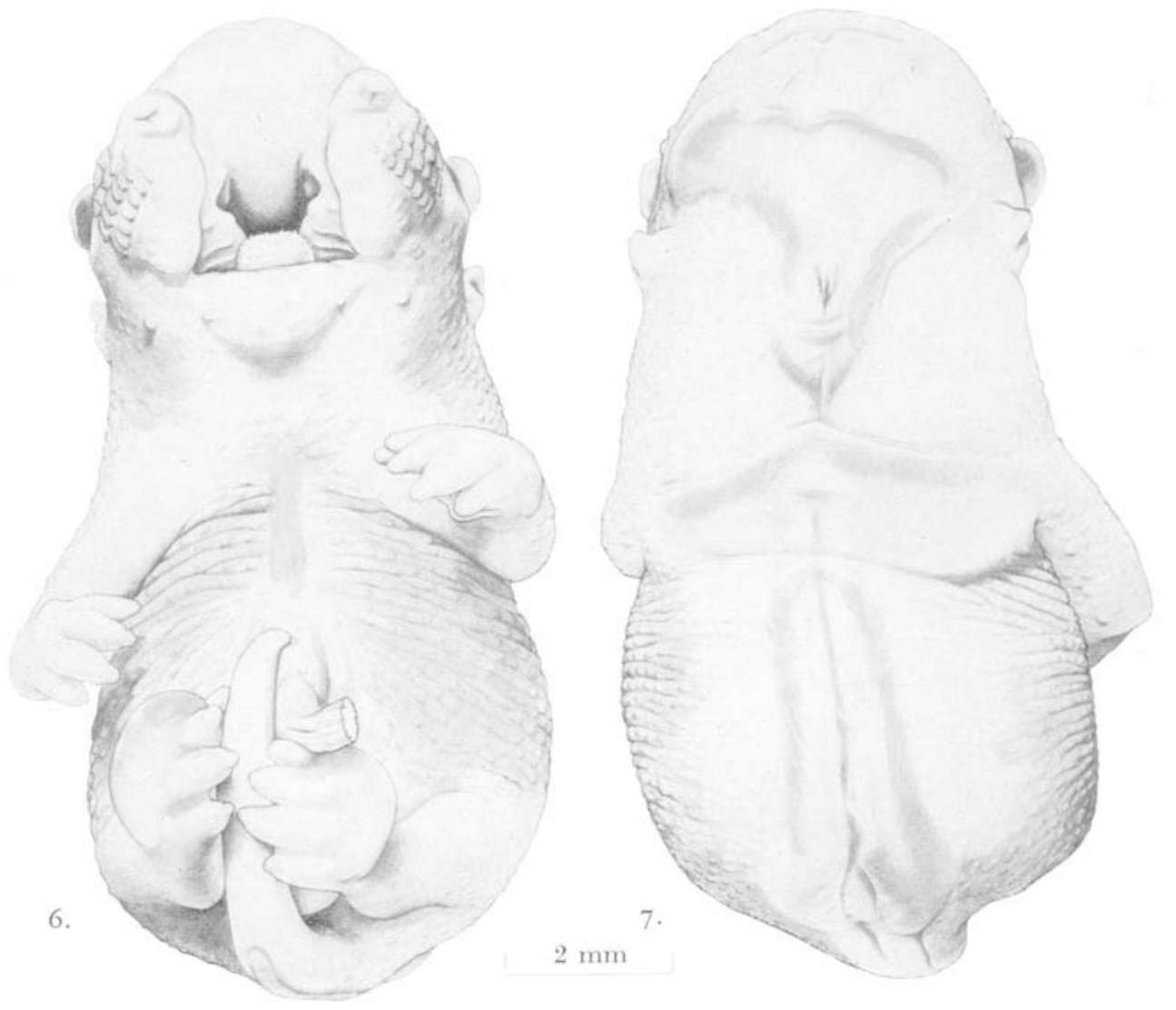

8.

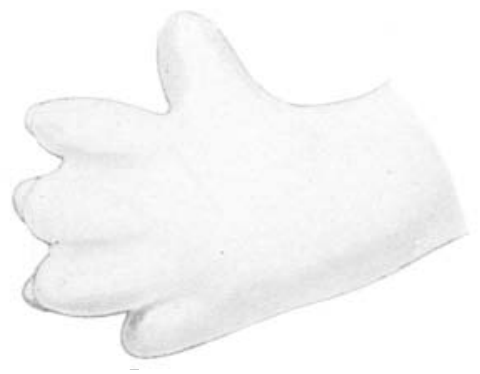

$$
2 \mathrm{~mm}
$$

Figs. 6 and 7 : ventral and dorsal views of a 16-day cleft-face $(P h / P h)$ embryo. Fig. 8: the left fore-limb of the same embryo.

H. GRÜNEBERG AND G. M. TRUSLOVE 


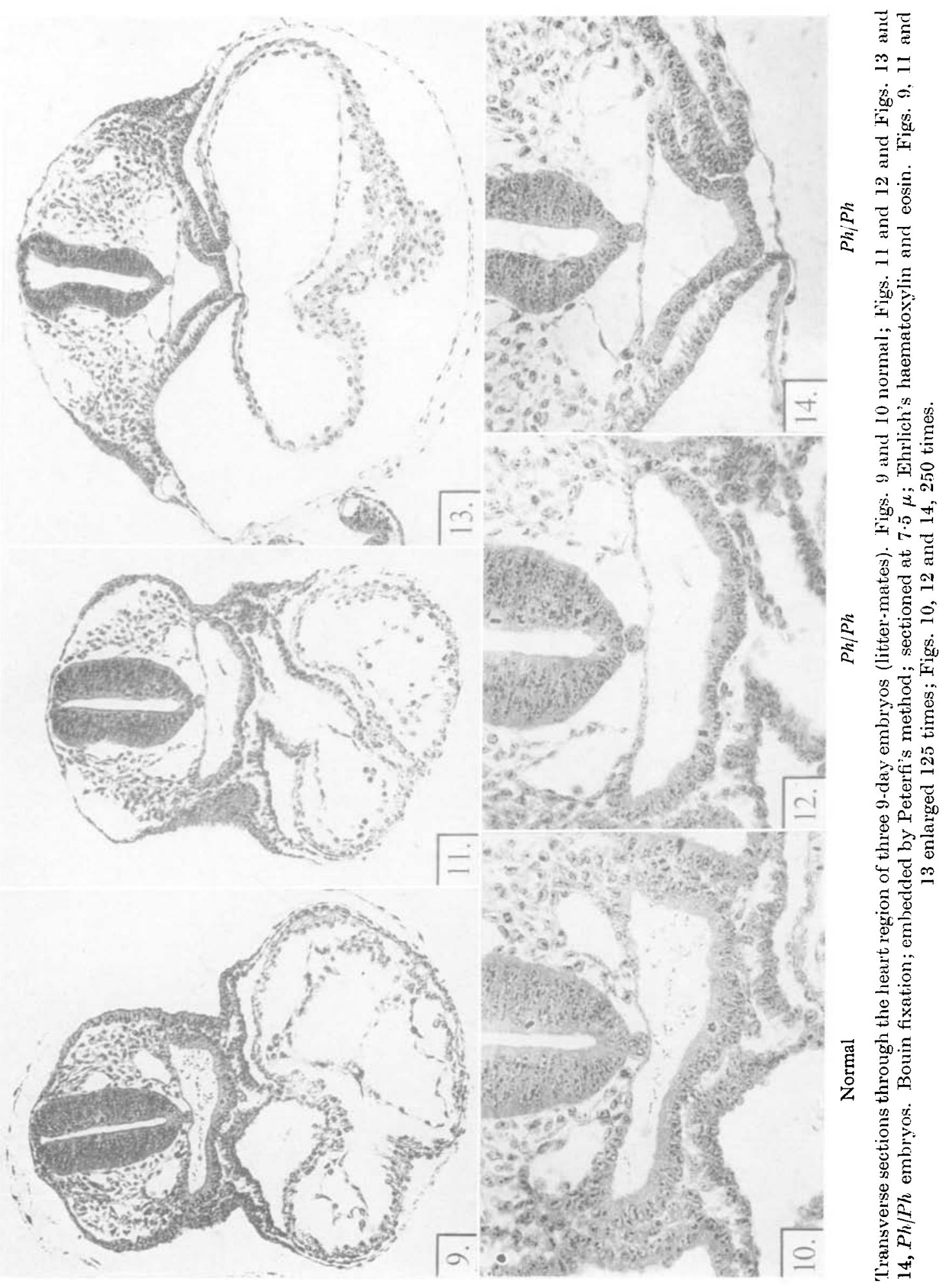

H. GRÜNEBERG aNd G. M. TRUSLOVE 